\title{
Evaluating Performance of Vietnamese Public Hospitals Based on Balanced Scorecard
}

\author{
Cuong Duc PHAM${ }^{1}$, Sen Thi VU², Yen Thi Kim PHAM ${ }^{3}$, Nam Thi VU \\ Received: March 20, 2020 Revised: April 11, 2020 Accepted: May 01, 2020
}

\begin{abstract}
The study evaluates the performance of public hospitals in Vietnam by applying the Balanced Scorecard (BSC). The authors first review the literature to find the research gap of performance in public hospitals. Then, we built Likert questionnaires to collect data from more than 200 managers of public hospitals in the Northwestern provinces of Vietnam. The research uses correlation regression to evaluate the performance based on the influence of factors in the BSC model, including Strategic planning, Internal process, Finance, Mission, Customer, and Employee learning and growth. The results show that the performance of public hospitals in the research sample is influenced by the factors in the BSC model in descending order based on the regression coefficient as follows: Internal process, Finance, Mission, Strategic planning, Customer, Employee learning and growth. Based on the quantitative research findings, we continue by conducting some deep interviews with specialty to propose intensive recommendations about how to implement Mission, Internal process, Financial policies, etc. to managers in public hospitals with an aim to improve the performance of public hospitals in the Northwestern mountainous region of Vietnam. The lessons could be applied for other public hospitals in Vietnam and other jurisdictions that have similar conditions.
\end{abstract}

Keywords : Balanced Scorecard, Performance, Public Hospital, Vietnam.

JEL Classification Code: M40, M41

\section{Introduction}

Vietnamese Northwestern provinces are mountainous provinces located in the Northwest region with difficult socio-economic conditions where 12 ethnic groups of people living together. This is one of the poorest mountainous provinces compared to the whole country, so the State has many priority policies in the public sector, especially in the

${ }^{1}$ First Author. Associate Professor, School of Accounting and Auditing, The National Economics University, Vietnam [Postal Address: 207 Giai Phong Road, Dong Tam Ward, Hai Ba Trung District, Hanoi, 116000, Vietnam] Email: cuongpd@neu.edu.vn

${ }^{2}$ Corresponding Author. Head, Accounting Department, Economic Faculty, Tay Bac University, Vietnam. Email: senketoan@utb.edu.vn ${ }^{3}$ Lecturer, Economics Faculty, Vinh University, Vietnam. Email: kimyenkt186@gmail.com

${ }^{4}$ Lecturer. Economics and Management Faculty, Thuyloi University, Vietnam. Email: namvt@tlu.edu.vn

(c) Copyright: The Author(s)

This is an Open Access article distributed under the terms of the Creative Commons Attribution Non-Commercial License (http://Creativecommons.org/licenses/by-nc/4.0/) which permits unrestricted noncommercial use, distribution, and reproduction in any medium, provided the original work is properly cited. field of health and education, including public hospitals. In the context of difficult socio-economic conditions of a mountainous province, the public hospitals have made great contributions to the implementation of the provincial people's healthcare mission. However, due to the current practical requirements of health care needs and demands, the hospitals of the whole country, in general, and Northwestern provinces, in particular, raised the question of how to improve health care, provide high-quality service, meet the requirements and please the patients.

On the other hand, through seeking opinions from some hospital managers, it is revealed that the problem is related to improving human resources in healthcare, processes, quality of medical services provided and responding to patients above their expectations. From a financial perspective, how to have higher hospitals' revenues, how to manage expenditures effectively, and by what way to increase investment in healthcare for each province, etc. are questions raised by hospital managers and lawmakers. Therefore, it is very important to assess the performance of public hospitals to recognize which factors have essential effects on hospitals' performance in order to improve the performance of public hospitals in the Northwestern provinces of Vietnam. 
BSC has been widely applied in evaluating for-profit businesses in the world. Voelker et al. (2001) suggest that the usage of BSC was assessed as a good management tool. BSC is applied by many businesses and organizations in both financial and non-financial assessments (Tran, 2019; Yang, Lee, and Chang, 2019; Nguyen, et al., 2019). However, after more than 20 years of research and application, there exists a gap (Hoque, 2014). For the health and hospital sector, it has been emerging in some studies. For instance, Aidemark (2001) investigates the application of balanced scorecards in a health care organisation. The author analyses a top-down control system, built on measurement, in a medical professional context, where auditing of systematic performance meets resistance. The paper reports that the balanced scorecards are seen to reduce both the ambiguity of performance evaluation and the goal incongruence between parties in the organisation. Also, according to Northcontt and France (2005), it is necessary to monitor and effectively manage the hospital because of its complex operation. Therefore, effective management is a challenge, in which quality care is difficult to measure. Hospitals often tend to focus long-term results on quality, while financial performance is all but one aspect, not the end result for this type of unit (Behrouzi, Shaharoun, \& Maaram, 2014). This study also confirmed that the use of BSC to assess hospitals is highly appropriate. Despite this emerging analytical tool, the studies about BSC in not-for-profit organizations are still limited (Zelman, Pink, Matthias, 2003).

The authors conduct an overview to see whether the Vietnamese public sector is assessed based on the BSC. Combining qualitative and quantitative research methods, the authors have studied the level of influence of financial and non-financial factors that belong to BSC to the public hospitals' performance in the context of the Northwestern provinces of Vietnam. This is the basis for proposing recommendations that can be applied in Vietnam and other similar jurisdictions.

\section{Literature Review}

BSC was developed by Kaplan and Norton (1992) as a means of assessing the financial and non-financial performance of an organization to achieve its mission goals. BSC measures the performance of a profit organization primarily by collecting data from four aspects of the organization: Customer, Internal process, Learning and development, and Finance. Based on the foundation of this initial BSC model, there are many different studies applying this model in evaluating the performance of the public and health sectors.

\section{About hospital performance:}

$\mathrm{Vu}$ (2013) argues that hospital performance is the extent to which services are provided, hospitals contribute to improving patient health, consistent with the expectations of patients and ensure fairness in providing medical care. According to Ionete et al. (2015) the hospital performance reflects the quality results of medical actions and the ability to manage available resources for people to receive appropriate health conditions, ensuring patient satisfaction.

\section{About aspects of the BSC for the public sector:}

Customer aspect: Kaplan and Norton (2001) define the Customer aspect as focusing on organizational methods and practices to develop values that meet consumer requirements. Based on the customer evaluation information, it is the basis for determining the performance for the remaining aspects such as the Internal process, Employee Learning and Growth, and Finance. In a non-profit organization, the customer aspect will be more important than other aspects because customer satisfaction is the result of the organization's mission achievement (Niven, 2008; Kaplan and Norton, 2001).

Financial aspect: Kaplan and Norton (2001) identify in a non-profit organization the Financial aspect which will test the performance of using the best cost in terms of ensuring benefits for customers. Niven (2008) also argues that the Financial aspect of non-profit organizations is indispensable because, through this aspect, the information will be collected on the use of limited resources and funds from the state budget and donors to provide quality services.

Internal process aspect: This is a term used in the nonprofit organization to replace the Internal business process aspect of a business organization. Kaplan and Norton (2001) define the aspect of the Internal process as focusing on methods and organizational practices to fully implement the expectations of customers and stakeholders. Improving performance, achieving organizational goals depends on the improvement of Internal processes.

Employee learning and growth: This is a term used in a non-profit organization to replace the Learning and development aspect of a business organization. This aspect identifies the Employee learning and growth process which include organizational practices and methods to promote organizational innovation, improvement and development (Kaplan and Norton, 2001). According to Niven (2008), in a non-profit organization, the success of an organization depends on the skills and capabilities of its employees.

\section{BSC factors affect organizational performance:}

According to the contingency theory, the factors affecting the performance of the organization include internal and external factors (Mintzberg, 1979). Owen et al. (2001) also argued that the main factors that reduce the performance of the organization are lacking understanding of the external environment, strategic vision, strategic vision, link between customer and internal processes. 
For-profit organizations: Many studies are showing the influence of the aspects of BSC on business performance in enterprises, in which a case study by Sharabati \& Fugaha (2014) has shown the positive impact and strong influence of four aspects: Customers, Internal business processes, Learning and Growth, Finance on business performance of Jordan pharmaceutical enterprises. The degree of influence of the above four aspects of business performance in the study amounts to $83.6 \%$, of which the Customer aspect has the largest impact on the performance of the business. Based on the contingency theory and BSC methodology, Zuriekat (2005 provides a research model showing the factors affecting the organization's performance according to the BSC aspects. It includes nine factors: Financial performance, Customers, Internal processes, Innovation, Employees, Suppliers, Environment, Quality, and Community.

\section{For public and non-profit sectors:}

According to Moullin (2002) and Chen, Hou, and Chang (2012), a well-designed performance measuring system will ensure that the organization provides high-quality, costperformance services to meet the needs of users. However, the performance measurement in the public services sector is complicated because it involves many stakeholders. This study has identified the necessary factors affecting the performance in the health sector such as Clinical process, Patient satisfaction, Cost control, Human resource factors, etc.

Blackmon (2008) used quantitative research methods to test the performance of the organization through the aspects of BSC. The research results show that the independent variables, including Strategic Planning, Mission, Customer, Internal Processes, Employee Learning and Growth, and Finance, have a positive impact on the dependent variable as the performance of the organization, in which the Financial aspect has a coefficient $\beta$ which is the largest in the regression, thus producing the greatest impact on the factors affecting non-profit organization efficiency. More specifically:

- Strategic planning factor: This factor reflects strategic planning activities, standards and measures to implement the strategic plan, the link between the strategic plan and the organization's mission. Giffords and Dina (2004) also have similar result on this issue.

- Mission factor: This factor reflects the link between the mission and decision-making, implementation of activities, priority order to complete the mission. At the same time, it reflects the connection of mission, vision, value to the strategy, the feasibility of the organization's strategy. Naranjo (2009) also agrees with this statement.

- Customer factor: This factor reflects customer satisfaction with the quantity and quality of services provided, meeting customer expectations and needs. Naranjo (2009) also has this result.

- Internal process factor: This factor includes indicator variables that reflect the ability to provide services, the quality of services provided, and the process and organization of the service delivery according to quality standards and service delivery management. Naranjo (2009) and Nerenz and Neil (2001) also report about this issue.

- Employee learning and growth factor: This factor includes indicator variables that reflect the working environment, satisfaction of employees, perceived by employees to work, the level of training to meet the requirements of job and employee skill level.

- Financial factor: This factor includes indicators for measuring revenues, expenditures and managing the efficient use of financial resources.

About the dependent variable, Blackmon (2008) used indicators that measure the improvement and change of the organization in terms of general aggregates that reflect all financial and non-financial performance of the organization.

Inheriting the quantitative research method and organizational performance indicators from the research, Blackmon (2008) and Franklin (2011) built a model to examine the correlation of influence between strategic planning and organizational performance based on five basic aspects of BSC in a non-profit organization. The research results have shown that the strategic plan and aspects of BSC are closely correlated. Increased impact on the strategic plan will increase the performance of the organization. Consequently, strengthening solutions that impact on BSC aspects will positively promote non-profit organization performance.

Research results by Ghoneim and Baradei (2013) showed the factors positively affecting the performance of Egyptian non-profit organizations, including: Strategic Planning, Mission, Internal Process, Customer, and Finance. And the factors Employee Learning and Growth, Volunteers are not statistically significant impact on the performance of Egyptian non-profit organizations.

Weerasooriya and Khatibi (2015) have studied the impact of these factors on the performance of the educational institutions and NGOs in Sri Lanka and they found that there are four factors that significantly affect the performance of the non-profits organizations, including: Strategic planning, Internal Processes, Customer, Employee Learning and Growth. However, the Finance and Volunteer factors do not impact significantly on the performance.

Thus, applying BSC to evaluate the organizational performance shows that there are many factors and the degree of influence of these factors on different performances. Inheriting the results of the above studies, the 
authors developed a research model as a basis to evaluate the organizational performance of public hospitals in the mountainous Northwestern provinces as a case study for Vietnam.

\section{Research Methodology}

\subsection{Research Model}

Based on the literature review of determinants affecting the performance by the method BSC indicated above, we applied the study by Blackmon (2008) and recommend the research model as shown in Figure 1.

Based on the literature review and research model above, the authors propose the following research hypotheses:

Hypothesis $\left(\mathrm{H}_{1}\right)$ : The Strategic planning factor has a positive effect on Hospital's Performance.

Hypothesis $\left(\mathrm{H}_{2}\right)$ : The Mission factor has a positive effect on Hospital's Performance.

Hypothesis $\left(\mathrm{H}_{3}\right)$ : The Customer factor has a positive effect on Hospital's Performance.

Hypothesis $\left(\mathrm{H}_{4}\right)$ : The Internal Process factor has a positive effect on Hospital's Performance.

Hypothesis $\left(\mathrm{H}_{5}\right)$ : The factor Employee Learning and Growth has a positive effect on the Hospital's Performance.

Hypothesis $\left(\mathrm{H}_{6}\right)$ : The Financial factor has a positive effect on Hospital's Performance.

\subsection{Data Source and Collection}

Primary data were collected based on both qualitative and quantitative studies as follows:

Qualitative research method: The data obtained from in-depth interviews are as follows: Based on the research overview, the authors synthesize the system of measurement criteria on the aspects of BSC as a basis for building the questionnaire. We conducted semi-structured interviews with hospital managers including heads, deputy heads,

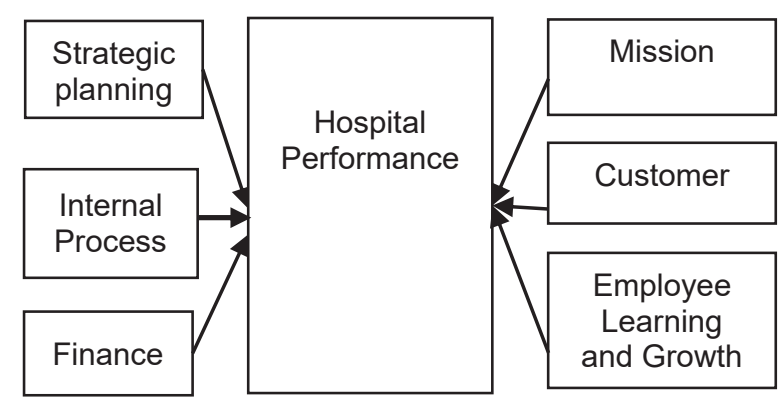

Figure 1: Proposed Research Model chief accountant, general accountant, and patients in public hospitals of Son La province. This research step aims at eliminating inappropriate targets and adding appropriate criteria in the factors affecting hospital performance. The results obtained in this research step are used to build survey questionnaires for quantitative research.

Quantitative research method: Respondents to the survey questionnaires were managers at the head of the department, deputy head, and board of directors of public hospitals in Northwestern provinces. The questionnaire include Part 1: General information about respondents such as age, gender, number of years of work, qualifications, position, number of years of position, hospital grade, and hospital size; Part 2 includes questions about the Strategic Planning in the form of "Yes" or "No" answers; Sections 3 to 8 include questions using the 5-point Likert scale - 1 is absolute disagree, 2 is disagree, 3 is neutral, 4 is agree and 5 is absolute agree: Part 3 has questions about Mission; Part 4 has questions about Internal Processes; Part 5 includes questions about Customer aspect; Part 6 includes questions on the aspect of Employee Learning and Growth; Part 7 asks questions about the Finance aspect; Part 8 asks questions about hospital performance by assessing change and improving hospital performance.

The number of delivered questionnaires was $400 ; 315$ were received. The received questionnaires were checked to eliminate the unsatisfied conditions. As a result, 203 questionnaires were valid for analysis and statistical test. According to Tran (2013), the minimum sample size with different overall levels ranges from 83-100 samples. Therefore, a sample size of 203 satisfied the research requirements.

\subsection{Data Analysis}

203 valid questionnaires we coded on SPSS 22 software and processed according to the following steps: Firstly, the authors performed the reliability test of the scale by Cronbach's Alpha; variables are accepted if the reliability coefficient is $>0.7$, and observed variables with total correlation coefficient less than 0.3 . The observed variables that ensure reliability are transferred to the Exploratory Factor Analysis (EFA) step to extract observation variables that are converging and separate with load factor $>0.5$ and $0.5<\mathrm{KOM}<1$, with Bartlett test having Sig $<0.05$ and variance extracted $>50 \%$ (Hoang and Chu, 2008). In the next step, the authors performed a regression analysis to evaluate the impact of factors on the dependent variable. Factors with a large coefficient will have a high effect on the dependent variable, while a positive $\beta$ coefficient has a positive effect with a dependent variable, $\beta$ with a negative sign has the opposite effect. The results obtained by the coefficient $\beta$ is the basis of the authors' conclusion for the research hypotheses set forth above, and the evaluation of the performance of 
public hospitals in Northwestern provinces through factors influence in the regression model.

In the regression equation, the ratio $\mathrm{R}^{2}$ indicates the percentage change of the dependent variable explained by the independent variables included in the model, so that the high ratio of $\mathrm{R}^{2}$ showing the impact of the independent variable up to the dependent variable gets bigger and vice versa.

\section{Research Results}

The results of EFA eliminated observed variables with load factor $<0.5$, resulting in the following six convergence and separation factors:

According to Table 1, the load factor in the standard assurance factors is $>0.5$ (from 0.513 to 0.875 ). At the same

Table 1: Cronbach's Alpha coefficient and the load factor of the variables in each factor

\begin{tabular}{|c|c|c|c|c|c|c|c|c|c|}
\hline \multirow{2}{*}{ Variables } & \multicolumn{6}{|c|}{ Component } & \multirow[t]{2}{*}{$\begin{array}{c}\text { Cronbach's } \\
\text { Alpha }\end{array}$} & \multirow[t]{2}{*}{$\begin{array}{c}\text { Number of } \\
\text { items }\end{array}$} & \multirow[t]{2}{*}{ Factor } \\
\hline & 1 & 2 & 3 & 4 & 5 & 6 & & & \\
\hline QT7 & 0.839 & & & & & & \multirow{8}{*}{0.931} & \multirow{8}{*}{8} & \multirow{8}{*}{$\begin{array}{c}\text { Internal Process } \\
\text { (QTNB) }\end{array}$} \\
\hline QT6 & 0.830 & & & & & & & & \\
\hline QT4 & 0.791 & & & & & & & & \\
\hline QT5 & 0.757 & & & & & & & & \\
\hline QT2 & 0.752 & & & & & & & & \\
\hline QT9 & 0.726 & & & & & & & & \\
\hline QT1 & 0.695 & & & & & & & & \\
\hline QT8 & 0.685 & & & & & & & & \\
\hline SM7 & & 0.798 & & & & & \multirow{7}{*}{0.896} & \multirow{7}{*}{7} & \multirow{7}{*}{ Mission (SM) } \\
\hline SM5 & & 0.791 & & & & & & & \\
\hline SM8 & & 0.775 & & & & & & & \\
\hline SM4 & & 0.722 & & & & & & & \\
\hline SM3 & & 0.705 & & & & & & & \\
\hline SM9 & & 0.682 & & & & & & & \\
\hline SM2 & & 0.513 & & & & & & & \\
\hline DT6 & & & 0.822 & & & & \multirow{6}{*}{0.880} & \multirow{6}{*}{6} & \multirow{6}{*}{$\begin{array}{l}\text { Employee Learning } \\
\text { and Growth } \\
\text { (DT\&PTNV) }\end{array}$} \\
\hline DT5 & & & 0.771 & & & & & & \\
\hline DT7 & & & 0.725 & & & & & & \\
\hline DT8 & & & 0.712 & & & & & & \\
\hline DT2 & & & 0.589 & & & & & & \\
\hline DT1 & & & 0.579 & & & & & & \\
\hline KC5 & & & & 0.875 & & & \multirow{5}{*}{0.856} & \multirow{5}{*}{5} & \multirow{5}{*}{$\begin{array}{l}\text { Strategy Planning } \\
\text { (KHCL) }\end{array}$} \\
\hline KC3 & & & & 0.800 & & & & & \\
\hline $\mathrm{KC} 2$ & & & & 0.790 & & & & & \\
\hline KC4 & & & & 0.772 & & & & & \\
\hline $\mathrm{KC} 1$ & & & & 0.639 & & & & & \\
\hline $\mathrm{KH} 3$ & & & & & 0.857 & & \multirow{4}{*}{0.880} & \multirow{4}{*}{4} & \multirow{4}{*}{ Customer (KH) } \\
\hline $\mathrm{KH} 2$ & & & & & 0.783 & & & & \\
\hline $\mathrm{KH} 4$ & & & & & 0.743 & & & & \\
\hline $\mathrm{KH} 1$ & & & & & 0.695 & & & & \\
\hline TC6 & & & & & & 0.863 & \multirow{3}{*}{0.784} & \multirow{3}{*}{3} & \multirow{3}{*}{ Finance (TC) } \\
\hline TC8 & & & & & & 0.791 & & & \\
\hline TC7 & & & & & & 0.634 & & & \\
\hline
\end{tabular}


time, the authors tested the reliability of the scale in the above factors to achieve the standard results of the coefficient of Cronbach's Alpha> 0.7 (from 0.784 to 0.931). Therefore, these six factors ensure the standard of the regression model to evaluate the influence of each factor on the performance of public hospitals in the Northwestern provinces of Vietnam.

According to Table $2, \mathrm{KMO}=0.872$, so factor analysis is appropriate. With Bartlett's test with Sig $<0.000$ and the variance of Total Variance Explained is 69\%>50\% (according to the standard), this proves $69 \%$ of the data variability is explained by the 6 factors above.

Table 2: KMO \& Bartlett's Test coefficients

\begin{tabular}{|c|c|c|}
\hline \multicolumn{2}{|c|}{$\begin{array}{c}\text { Kaiser-Meyer-Olkin Measure of } \\
\text { Sampling Adequacy. }\end{array}$} & .872 \\
\hline \multirow{3}{*}{$\begin{array}{c}\text { Bartlett's Test of } \\
\text { Sphericit }\end{array}$} & 4713.855 & 5721.547 \\
\cline { 2 - 3 } & 528 & 325 \\
\hline
\end{tabular}

Results of running the regression model obtained the results:

Table 3, with $\mathrm{R}^{2}=0.536$, means $53.6 \%$ change in the dependent variable the performance is explained by six independent variables based on the aspects of BSC according to the proposed model including Strategic Planning; Mission; Customer; Internal Process; Employee Learning and Growth; Finance.

Table 4, with $\mathrm{F}=37,715$, Sig $=0.000<0.05$, therefore rejects the hypothesis that the entire regression coefficient is zero, accepting the hypothesis that a linear relationship exists between the dependent variable Hospital Performance and the independent variables.

The results of regression models of factors affecting the Hospital Performance are obtained in Table 5 below:

Based on the results of Table 5, the dependent variable "Hospital Performance" is determined:

Hospital Performance (Y)

$=0.435+0.089 * K H C L+0.125 * S M+0.475 * Q T N B$

$+0.072 * K H+0.053 * D T \& P T N V+0.146 * T C$

Table 3: Model Summary Model Summaryb

\begin{tabular}{|c|c|c|c|c|c|}
\hline Model & $\mathbf{R}$ & $\mathbf{R}^{\mathbf{2}}$ & Adj. $\mathbf{R}^{\mathbf{2}}$ & Std. Error & Durbin-Watson \\
\hline 1 & $.732^{\mathrm{a}}$ & .536 & .522 & .334 & 2.079 \\
\hline
\end{tabular}

Table 4: ANOVA coefficient

\begin{tabular}{|l|c|c|c|c|c|c|}
\hline \multicolumn{2}{|c|}{ Model } & Sum of Squares & df & Mean Square & F & Sig. \\
\hline \multirow{4}{*}{1} & Regression & 25.187 & 6 & 4.198 & 37.715 & $.000 \mathrm{~b}$ \\
\cline { 2 - 6 } & Residual & 21.816 & 197 & .111 & & \\
\cline { 2 - 6 } & Total & 47.003 & 203 & & \\
\hline
\end{tabular}

Table 5: Regression results in the research model Coefficients

\begin{tabular}{|c|c|c|c|c|c|c|c|c|}
\hline \multirow{2}{*}{\multicolumn{2}{|c|}{$\begin{array}{l}\text { Model } \\
\text { B }\end{array}$}} & \multicolumn{2}{|c|}{$\begin{array}{l}\text { Unstandardized } \\
\text { Coefficients }\end{array}$} & \multirow[t]{2}{*}{$\begin{array}{c}\text { Standardized } \\
\text { Coefficients }\end{array}$} & \multirow[t]{2}{*}{$\mathbf{T}$} & \multirow{2}{*}{$\begin{array}{c}\text { Sig. } \\
\text { Tolerance }\end{array}$} & \multicolumn{2}{|c|}{$\begin{array}{l}\text { Collinearity } \\
\text { Statistics }\end{array}$} \\
\hline & & Std. Error & Beta & & & & VIF & \\
\hline \multirow{7}{*}{1} & (Constant) & .435 & .244 & & 1.780 & .077 & & \\
\hline & Internal Process & .487 & .067 & .475 & 7.275 & .000 & .556 & 1.798 \\
\hline & Mission & .115 & .054 & .125 & 2.125 & .035 & .688 & 1.452 \\
\hline & Strategy Planning & .181 & .107 & .089 & 1.700 & .091 & .858 & 1.165 \\
\hline & Customer & .073 & .062 & .072 & 1.174 & .242 & .628 & 1.593 \\
\hline & Employee Learning and Growth & .055 & .067 & .053 & .825 & .411 & .565 & 1.769 \\
\hline & Finance & .115 & .043 & .146 & 2.658 & .009 & .785 & 1.273 \\
\hline
\end{tabular}


The regression result has VIP $<3$, so the regression equation has no multicollinearity between the independent variables. Therefore, the regression model is accepted.

In Table 5, the independent variables in the model with coefficients $\beta>0$ and Sig $<0.05$ include: Finance, Mission, Internal process. Therefore, these factors have a positive effect on the Hospital Performance in the research sample with a statistical significance level of $95 \%$.

Levels of the positive impact of these factors on Hospital Performance are arranged in the descending order in the regression equation as follows: Internal process, Finance, Mission, Strategic planning, Customer, Employee learning and growth. In particular, the Internal process factor has a high coefficient of 0.475 compared to the remaining factors showing the greatest influence and the most important role, the Employee learning and growth factor has the lowest level of influence with $\beta=0.053$. Concluded testing of hypotheses as follows (see Table 6):

\section{Discussion}

The research results show that, among six factors of the research model, three factors have statistical significance level of 5 percent: Mission, Internal process, Finance have a positive impact on the performance of public hospitals in the research sample. The results also indicate that the research model explained $53.6 \%$ of the change in the hospital performance due to independent variables in the regression equation.
From quantitative analysis results combined with in-depth interviews, the authors propose some recommendations to improve the performance of public hospitals in Northwestern provinces of Vietnam. The priority order of proposals is based on the influence of the statistical factors in the conclusion of the research hypotheses as follows:

\section{About Internal process perspective:}

The research results show that hypothesis $\mathrm{H}_{4}$ is accepted, that is, the Internal process has a positive impact on the performance of public hospitals in Northwestern provinces, at statistically significant level of 5 per cent. At the same time, this factor has the largest coefficient $\beta$ in the regression equation, so it has the largest influence on the factors of the model. This result is consistent with previous studies conducted by Lee (2006), Ghoneim and Baradei (2013), and Weerasooriya and Khatib (2014). This is unlikely for for-profit-organizations where organizational innovation, including "innovation in business practices" and "innovation in workplace organization," are significantly positively associated with firm performance (Phan, 2019; Tran, 2017). Based on the research results, to promote the efficiency of operation of hospitals in this area, it is necessary to strengthen the internal process solution on criteria that have been statistically tested. More specifically, the authors propose some following recommendations:

Firstly, the planning for hospital activities should be based on the mission to guide all hospital activities in practice to achieve high efficiency.

Table 6: Summary of conclusions for research hypotheses

\begin{tabular}{|l|c|c|l|}
\hline \multicolumn{1}{|c|}{ Factor } & Beta $(\boldsymbol{\beta})$ & Sig. & \multicolumn{1}{c|}{ Conclude } \\
\hline $\begin{array}{l}\text { Strategy planning } \\
\text { (KHCL) }\end{array}$ & 0.089 & 0.091 & $\begin{array}{l}\text { There is a positive relationship between the Strategic planning } \\
\text { factor and the Hospital Performance. However, sig coefficient> } 0.05 . \\
\text { Therefore, there is no basis to accept the hypothesis }\left(\mathrm{H}_{1}\right) .\end{array}$ \\
\hline Mission (SM) & 0.125 & 0.035 & $\begin{array}{l}\text { There is a positive influence relationship between the Mission factor } \\
\text { and the Hospital performance, ensuring statistical significance } \\
\text { level>95\%. Therefore, the hypothesis }\left(\mathrm{H}_{2}\right) \text { is accepted. }\end{array}$ \\
\hline Customer (KH) & 0.072 & 0.242 & $\begin{array}{l}\text { There is a positive relationship between the Customer factor and the } \\
\text { Hospital performance. However, sig coefficient> 0.05. Therefore, there } \\
\text { is no basis to accept the hypothesis }\left(\mathrm{H}_{3}\right)\end{array}$ \\
\hline $\begin{array}{l}\text { Internal process } \\
\text { (QTNB) }\end{array}$ & 0.475 & 0.000 & $\begin{array}{l}\text { There is a positive influence relationship between the Internal process } \\
\text { factor and the Hospital performance, ensuring statistical significance } \\
\text { level> 95\%. Therefore, the hypothesis }\left(\mathrm{H}_{4}\right) \text { is accepted }\end{array}$ \\
\hline $\begin{array}{l}\text { Employee learning } \\
\text { and growth } \\
\text { (DT\&PTNV) }\end{array}$ & 0.053 & 0.411 & $\begin{array}{l}\text { There is a positive relationship between the Employee learning and } \\
\text { growth factor and the Hospital performance. However, sig coefficient> } \\
\text { 0.05. Therefore, there is no base to accept the hypothesis }\left(\mathrm{H}_{5}\right)\end{array}$ \\
\hline Finance (TC) & 0.146 & 0.009 & $\begin{array}{l}\text { There is a positive influence relationship between the Finance factor } \\
\text { and the Hospital performance, ensuring statistical significance level> } \\
\text { 95\%. Therefore, the hypothesis }\left(\mathrm{H}_{6}\right) \text { is accepted }\end{array}$ \\
\hline
\end{tabular}


Secondly, the quality of service provided: The characteristic of medical services is healthcare, so the quality of service provided is very important for patients to choose and be assured of examination. and treatment of disease. Many previous reports show that the issue of ensuring quality of health services of hospitals in Vietnam is still limited, many patients are still not satisfied with the quality of examination and treatment diseases, especially at district hospitals. Therefore, in order for patients to be more satisfied with the service quality, hospitals should focus on solutions to improve service quality. At the same time, quality control on process elements and methods of supply meets the quality standards issued by the Ministry of Health. Improving the quality of health services will enhance operational efficiency for public hospitals in the provinces of Vietnam.

Thirdly, in terms of management in the implementation of internal procedures, the hospitals should use the operating and working regulations tool to manage employees and hospital activities. As a result of in-depth interviews with some key staff at the Northwestern hospitals, it indicates that the operational regulations and working regulations have a huge impact on the organizations. On the other hand, this is a tool to test, control and evaluate emulation and discipline in the hospital. It is very important to promote the improvement of this tool to meet the requirements of the management, so that hospitals should improve this regulation, helping to improve the effectiveness of hospital operations.

Fourthly, according to the research results, the hospital management should try to achieve the hospital mission in the most conveniently and effectively. Therefore, the management needs to be always innovative and creative in all circumstances in order to achieve the mission for hospitals of the mountainous provinces. The performance of hospitals is always to achieve the goal of health care for the people and ethnic minorities in the local conditions with many limitations and socio-economic difficulties of the mountainous Northwestern region of Vietnam.

Thus, this factor plays a very important role in affecting the performance of public hospitals in the Northwestern provinces of Vietnam. The results of the study reflect the current practice of the mission as evaluation criteria in public hospitals in the Northwestern provinces. Therefore, hospital managers need to pay attention on this aspect to improve the hospital performance further in the future.

\section{About Financial perspective:}

The research results show that the hypothesis $\mathrm{H}_{6}$ is accepted, meaning that there is a positive impact of the Financial factor on the hospital performance. This is the second most influential factor in the research model. This result is also consistent with Blackmon (2008) and Franklin (2011). Upon the result, in order to strengthen financial solutions to promote the efficiency of public hospitals in the research sample, the hospital managers as well as the managing agency, and the Ministry of Health, should focus on the following solution:

Firstly, increasing revenues from hospital fees will ensure the ratio of total expenses to the total recurrent spending in hospitals increases. This means that the hospital has increased its financial autonomy at the request of the Government and the Ministry of Health (Government, 2015). To increase revenue, hospitals must constantly improve the quality of medical services provided, increase patient satisfaction in order to increase the attraction of patients who trust examination and treatment. Current hospital fee revenues include hospital fees from patients with health insurance and hospital fees for no-healthcareinsurance patients, in which hospital fee revenues from withhealthcare-insurance patients account for up to $96 \%$. This rate is very high compared to the whole country, because patients in the research provinces are mostly ethnic people, remote areas and disadvantaged areas should be given priority on health insurance policy. There should be a source of support from the state budget, a priority policy to help ethnic minorities and the poor have access to health care. However, when interviewing patients, many still do not trust the quality of services of district and provincial hospitals. Therefore, the current condition of transport infrastructure is developed, vehicles are more convenient, so many patients choose to have medical examination and treatment at the central level, even though they have to accept the payment of all the expenses or enjoy low health insurance benefits due to inappropriate routes. Many people can afford to pay for high quality treatment, but the hospitals in the research provinces do not meet the requirements. As a result, a large proportion of financial resources from these subjects are currently unable to attract hospitals in the provinces. Therefore, solutions to satisfy and meet the diverse needs of patients on service quality should be focused on implementation in the future to be able to increase revenue in a sustainable manner.

Secondly, according to the results of interviews with hospital managers, it is necessary to increase the financial support from the state budget to invest in facilities for clinics, treatment rooms and canteens, etc. in some spacious and well-equipped hospitals at the district hospital to better meet the quality of medical examination and treatment requirements, making them more satisfied with patients and caregivers. Besides, solutions to increase hospital revenues can make socialization of external financial resources more attractive by attracting institutional and individual investors into the field of voluntary medical examination and treatment. Since then, there are financial resources for investment in modern equipment and facilities. At the same time, there are financial resources to invite good doctors working to develop medical examination and treatment services at the request of patients in the province. Having such high quality service, 
it will be a solution to reduce the proportion of referral patients and increase hospital revenues. However, in order to attract socialization resources, so that investors can feel secure and have investment expectations, it is necessary to have an effective roadmap for mobilizing and using capital, which benefits the whole family. For investment and society, it is necessary to research, survey and feasibly develop this project according to the appropriate roadmap.

Thirdly, within the revenue limits, hospitals need to use cost effectively within the annual budget to help the hospitals control their financial position. However, within the budget, how to use it rationally and effectively for hospitals activities is a very important question. In order to use cost effectively, it is necessary to appropriately allocate expenses for the main operating activities in the hospital such as: Administrative costs, costs of medicines, medical supplies, salaries, etc. According to the interview results, many health workers said that it is necessary to prioritize the allocation of salary costs, strengthen the regime for health workers in remote areas so that health workers are assured. This could lead to the loyalty of long-term work from healthcare staff.

Fourthly, according to the autonomy mechanism in public non-business units of the Vietnamese Government's Decree No. 16/2015 (Government, 2015), public nonbusiness units such as hospitals calculate the price of medical services according to the roadmap from now to 2020, public units such as hospitals will account for direct costs, salaries, management costs and the depreciation of fixed assets of service delivery assets. However, with the autonomy mechanism as above, district hospital leaders said the Government needs to revise the level of autonomy for hospitals in remote areas, while the equipment healthcare is limited, the quality of medical services is not enough attraction for those willing to pay at a high level. At the moment, district hospitals mostly ensure financial autonomy partly, the rest still need support from the state budget to make hospitals better perform their roles and functions. In addition, with poor district hospitals in the Northwest provinces the implementation of the regime of contracting the health insurance fund and apply the same ceiling price between hospitals of the same class across the country, this makes it difficult financial constraints for task performance. Therefore, it is necessary to have specific solutions to support district hospitals in mountainous areas on this issue.

\section{About Mission perspective:}

The hospital's mission is the reason for the hospital's establishment, survival and growth (Ghoneim and Baradei, 2013; Weerasooriya and Khatib, 2014). Therefore, the functions assigned to the hospital will be a motivation to all activities of hospitals towards achieving its mission. Especially, with the public hospitals of the province in difficult mountainous areas, the mission of the hospital must be towards equality and care for the people's health in ethnic minority and mountainous areas where many poor people live. Many ethnic minorities still have backward customs and practices in health care, and the infrastructure conditions for accessing health services are still difficult. To achieve this unique mission, the awareness of the roles, duties and work of each hospital employee is important in improving the quality of health care services and the patients' satisfaction, achieving the people's health care goals in the areas assigned by the Party and the Government. In addition, specific social policies on health care for ethnic minority, upland and disadvantaged areas need to be promoted for hospitals to achieve their mission.

The results show that the hospital mission is the third most influential factor. In order to focus on increasing performance through this factor, public hospitals in the province should:

Firstly, in many activities that managers need to perform, it is necessary to set priorities for the tasks to achieve the mission of the mountainous hospitals.

Secondly, it is necessary to set a long-term goal of the hospital and to realize the goal; it is necessary to be aware of the role of the strategy for the hospital's mission and implement the operational strategy.

Thirdly, in order to achieve the hospital mission, it is necessary to be aware of the performance of the task for each individual and all hospital staff. This has been implemented in hospitals, but it is not really thorough and effective. Therefore, it is necessary to increase the awareness of each hospital employee about the tasks and work responsibilities associated with the hospital's mission. Therefore, it is necessary to attach rights and obligations in the performance of specific tasks according to hospital management and operation regulations.

\section{Conclusion}

Using the qualitative research method combined with the quantitative research method, the authors evaluated the performance of public hospitals in Northwestern provinces based on the degree of influence of various factors. The factors, the aspects of BSC, show that three aspects are corresponding to the three factors that have the largest positive influence relationship and ensure statistical significance in the research model. In descending order of influence, these factors are: Internal process, Finance, and Mission. The remaining factors in the regression model include: Strategic planning, Customer, Employee learning and growth, which show a positive impact on the performance of public hospitals in the province. However, these factors have sig coefficient> 0.05 , so it does not guarantee statistical significance. Based 
on the above statistically significant factors, the paper has proposed to hospitals recommendations that focus on these factors to enhance the effectiveness of the public hospitals in the Northwestern provinces of Vietnam in the future.

\section{References}

Aidemark, L.G. (2001). The meaning of balanced scorecard in the health care organization, Financial Accountability and Management, 17(1), 23-40. https://doi.org/10.1111/1468-0408.00119

Behrouzi, F., Shaharoun, A.M., \& Maaram, A. (2014). Applications of the balanced scorecard for strategic management and performance measurement in the health sector, Australian Health Review, 38, 208-217. doi: 10.1071/AH13170

Blackmon, V. Y. (2008). Strategic planning and organizational performance: an investigation using the balanced scorecard in non-profit organizations. $\mathrm{PhD}$. Thesis, Capella University, United States.

Chen, H.F., Hou, Y.H., \& Chang, R.E. (2012). Application of the balanced scorecard to an academic medical center in Taiwan: the effect of warning systems on improvement of hospital performance, J Chin Med Assoc, 75(10), 530-539. doi: 10.1016/j.jcma.2012.07.007

Franklin, P. W. (2011). Relationship between Strategic Planning and Non-profit Organizational Performance, PhD Dissertation, Capella University, United States.

Ghoneim, N., \& Baradei, L. E. (2013), The Impact of Strategic Planning on Egyptian Non-profits' Performance: An Assessment Using the Balanced Scorecard, Journal of USChina Public Administration, 10, 57-76.

Giffords, E. D., \& Dina, R. P. (2004). Strategic planning in nonprofit organizations: Continuous quality performance improvement a case study, International Journal of Organization Theory and Behavior, 7(1), 66-80. DOI: 10.1504/IJSEI.2013.059318

Government of Vietnam (2015). Decree No. 16/2015/ND-CP Regulates autonomy for public non-business units, issued on February 14, 2015.

Hoque, Z. (2014). 20 years of studies on the balanced scorecard: Trends, accomplishments, gaps and opportunities for future research, The British Accounting Review, 46 (2014), 33-59. DOI:10.1016/j.bar.2013.10.003

Hoang, T., \& Chu, N. M. N. (2008). Data Analysis by SPSS. Hanoi: Hong Duc Publication House.

Ionete T.S., Toplicianu, V., \& Brezeanu, E. (2015). Performance in the public health system - is only a purely medical issue? Procedia Economics and Finance, 20 (2015), 301-307. https:// doi.org/10.1016/S2212-5671(15)00089-1

Kaplan, R.S., \& Norton D.P. (1992), The Balanced Scorecard: measures that drive performance, Harvard Business Review, January-February 1992 Issue
Kaplan, R.S., \& Norton, D.P. (2001). Transforming the Balanced scorecard from Performance Measurement to Strategic Management, Accounting Horizons, 15(2), 147-160.

Lee, N. (2006). Measuring the performance of public sector organisations: a case study on public schools in Malaysia, Measuring business excellence, 10(4), 50-64. https://doi. org/10.1108/13683040610719272

Mintzberg, H. (1994). The rise and fall of strategic planning, Harvard Business Review, January-February 1994.

Moullin, M. (2002). Delivering Excellence in Health and Social Care. London: Open University Press.

Naranjo, D. (2009). Implementation of strategies at the hospital, Health Care Management Review, 18(4), 667-695.

Nerenz, D.V., \& Neil, N. (2001). Performance Measures for Health Care Systems, Commissioned Paper for the Center for Health Management Research. Retrieved on 22 Feb. 2020 from: http:// www.hret.org/chmr/resources/cp19b.pdf

Nguyen, M. H, Mai, T. L., \& Huynh, T. L. (2019). The Role of Transformational Leadership toward Work Performance through Intrinsic Motivation: A Study in the Pharmaceutical Field in Vietnam, Journal of Asian Finance, Economics and Business, 6(4), 201-212. https://doi.org/10.13106/jafeb.2019. vol6.no4.201

Niven, P. R. (2008). Balanced scorecard step-by-step for government and non-profit agencies ( $2^{\text {nd }}$ ed.). New York, NY: John Wiley \& Sons, Inc. DOI: 10.1002/9781119197287.

Northcott, D., \& France, N. (2005). The Balanced Scorecard in New Zealand health sector performance management, Australian Accounting Review, 15(3), 34-46. https://doi. org/10.1111/j.1835-2561.2005.tb00301.x

Owen, K., Mundy, R., Guild, W., \& Guild, R. (2001). Creating and sustaining the high-performance organization, Managing Service Quality: An International Journal, 11(1), 10-21. https:// doi.org/10.1108/09604520110362443

Phan, T.T.A. (2019). Does organizational innovation always lead to better performance? A study of firms in Vietnam, Journal of Economics and Development, 21(1), 71-82 | DOI: 10.1108/ JED-06-2019-0006.

Sharabati, A. A., \& Fugaha, S. J. (2014). The Impact of Strategic Management on the Jordanian Pharmaceutical Manufacturing Organizations' Business Performance, International Review of Management and Business Research, 3(2), 668-687.

Tran, T. K. T. (2013). Survey of sociology, National Economics University Publishing House.

Tran, V. T. (2017). Application of BSC in assessing performance of listing companies, Financial Review, 9.

Tran, T.T. (2019). The Impact of Balanced Scorecard on Performance: The Case of Vietnamese Commercial Banks, Journal of Asian Finance, Economics and Business, 7(1), 7179. https://doi.org/10.13106/jafeb.2020.vol7.no1.71 
Voelker, K.E., Rakich, J.S., \& French, G.R. (2001). The balanced scorecard in healthcare organizations: a performance measurement and strategic planning methodology, Hosp Top, 79, 13-24.

Vu, A. D. (2013). Measuring Quality of Health Care Services, Department of Quality Management, Ministry of Health.

Weerasooriya, R. B., Khatibi, A., \& Alwis, A. D. (2014). The impact of strategic planning for training and educational nongovernment organizations in Srilanka: An evaluation using the Balanced Scorecard, International Journal of Management Sciences and Business Research, 3(7), 48-62.
Yang, M. H., Lee, T. R., \& Chang, T. C. (2019). Key Success Factors of Blockchain Platform for Micro-enterprises, Journal of Asian Finance, Economics and Business, 6(3), 283-293. https://doi. org/10.13106/jafeb.2019.vol6.no3.283

Zuriekat, K. (2005). Performance Measurement Systems: An Examination of the Influence of the Contextual Factors and Their Impact on Performance with a Specific Emphasis on the Balanced Scorecard Approach, University of Huddersfield

Zelman, W.N., Pink, G.H., \& Matthias, C.B. (2003). Use of the Balanced scorecard in healthcare, Journal of Health Care Finance, 29(4), 1-16. 